\title{
Evaluating Chinese Potential e-Commerce Websites based on Analytic Hierarchy Process
}

\author{
Hemn Barzan Abdalla, Liwei Wang \\ Department of Computer Science, College of Science and Technology \\ Wenzhou-Kean University, China
}

\begin{abstract}
China has recently become the largest market for e-commerce at the global level. After the technological revolution and its widespread, As of December 2020, about 782.41 million people deal with this e-commerce through modern and advanced electronic devices, which are smartphones, computers, and others. The study of e-commerce is one of the branches of business administration established electronically through the use of Internet networks, which aim to carry out buying and selling operations. This article applied the Analytic hierarchy process (AHP) to evaluate three potential Chinese e-Commerce websites: JD, TAOBAO, and SUNING. We divided our model into three primary levels: Goal level, Strategical level, and criteria level. We take two main factors into account at the Strategical level: website (A1) and user (A2). Meanwhile, in the criteria level, we consider the total of six aspects: Visiting speed (B1), website stability (B2), page ranking (B3), average person visits (B4), period of average person visits (B5), and users' comments (B6). We also make all scores normalized; all scores are mapped into 0-1 to compare each website's performance. Our results show the TAOBAO is the best E-commerce website with a score of 0.8233 based on our algorithm, and JD is the second one with a score of 0.7895 , while SUNING is the worst with a score of 0.5955 .
\end{abstract}

Keywords-Analytic hierarchy process (AHP); e-commerce; chinese e-commerce websites; JD (JING DONG); taobao; suning

\section{INTRODUCTION}

E-commerce is indubitably a growing up industry around the world. Nowadays, E-commerce is regarded as a necessary part, and a cutting-edge shopping mode around the world [1]. with the development of the surge of E-commerce, modern society is undergoing a considerable change. From the Perspective of the e-commerce platform, there are mainly several business models: B2B, B2C, B2E, B2G, B2M, C2B, C2C, G2B, G2C, G2E, G2G, and P2P [2]. Meanwhile, various E-commerce platforms and related websites are showing up. The competition among all E-commerce is so radical that some websites will be eliminated through selection or competition. In China, the number of Internet users and the logistics and express industry is overgrowing, e-commerce enterprises are in fierce competition, and the platform situation is taking shape. In the $\mathrm{C} 2 \mathrm{C}$ field, with the entry of search engine giant Baidu, online shopping users have more choices, and the industry competition is more intense. In this period, the pace of survival of the fittest in the e-commerce industry was accelerated, and the innovation of mode, product, and service appeared constantly [3].
With the growing maturity of online shopping, shopping demand has become diversified. In addition to continuously expanding categories, optimizing logistics, and after-sales service, manufacturers are increasingly developing their platform webpages. To compare and pick up high-level Ecommerce, a good and robust evaluation Model should be applied. There are different types of evaluation models based on different algorithms. This study employs the Analytic hierarchy process(AHP) to evaluate three potential Chinese Ecommerce websites: JD, TAOBAO, and SUNING. AHP has been bored out excellent performance in a wide range of research fields. It completely relies on subjective evaluation to prioritize the scheme, needs less data, and takes a short time to make a decision. On the whole, AHP introduces quantitative analysis into the complex decision-making process and makes full use of the preference information given by decisionmakers in pairwise comparison for analysis and decision support. It not only effectively absorbs the results of qualitative analysis but also gives full play to the advantages of quantitative analysis, so that the decision-making process is highly organized and scientific, it is especially suitable for decision analysis of social, economic system [4], [5], [6], [7], [8], [9], [10], [11], [12], [13], [14] utilized the AHP on project management. In other related fields, [15] 's research shows the APH could play an essential role in vendor selection of a telecommunications system. They found that AHP can be used to improve the group decision-making of selecting suppliers to meet customer requirements. AHP was applied to maritime transportation [16], Earth dam site selection [17], agricultural land suitability evaluation with the GIS platform [18] as well.

This paper's structures are as follows: first, the related work regarding the application of AHP on E-commerce will be introduced and discussed; next, a certain AHP model and its matrix are built for this scenario, and corresponding criteria and their definitions are selected; meanwhile, their measurements are quantified by scores. Finally, the results are compared and discussed.

\section{RELATED WORK}

There are already existed abundant researches regarding the application of AHP on E-commerce platform evaluations. [19] proposed a new evaluation model based on Analytical Hierarchy Process (AHP) and Dempster Shafer (DS) theory and applied it to study E-commerce websites with 27 variables. AHP is used to analyze the ranking problem's structure and determine the weights of the criteria for ranking $\mathrm{B} 2 \mathrm{C} \mathrm{E}$ - 
commerce websites [20]. Fuzzy AHP is employed as a product selection service in e-commerce [21]. System Quality, Content Quality, Usages, Table I: values of B1 and B2 at each time, the figure without () means average visiting time(s) of page, while the figure in () means ping time(ms) at each time.

Trust, Customer Support, Online Customer Feedback, and Personalization were considered when using ME-OWA and Fuzzy AHP to evaluationB2C E-commerce Websites. [22] proposed DSS based on an AHP method tcomprising three structured multi-criteria and sub-criteria for selecting the best possible choice from a set of alternatives. [23] evaluated the quality of e-commerce services using Fuzzy AHP and TOPSIS. [24] established a complete shipping efficiency evaluation system for cross-border e-commerce logistics and applies it to the Qingdao Port of China for solid evidence Based on the Analytic Hierarchy Process (AHP).[25] evaluated performance measurement indicators in the E-commerce logistics system based on the extent fuzzy analytic hierarchy process (AHP).[26]

Applied entropy method to establish a model to determine the objective weight of each index, and calculated the distance and close-degree between the e-commerce website and the ideal point. In addition, [27] was conducted to evaluate and select the quality of e-commerce services using Fuzzy AHP. [28] established B2C e-commerce site evaluation system, whose Perspective starts from consumer based on AHP.

This paper's contributions are mainly introducing some new related variables, especially the periodical variables like the Period of Average Person Visits which may be an essential index when studying the performance of customers. The wavelet technique is also employed in this study, which can filter periodical patterns [29].

TABLE I. Analyze the StRUcture of RANKING PROBLEM

\begin{tabular}{|c|c|c|c|}
\hline Try times & TaoBao & JD & Suning \\
\hline 1 & $\begin{array}{l}0.243 \\
(16.502)\end{array}$ & $\begin{array}{l}0.461 \\
(3.699)\end{array}$ & $\begin{array}{l}\mathbf{0 . 2 3 1} \\
(282.537)\end{array}$ \\
\hline 2 & $\begin{array}{l}0.222 \\
(15.689)\end{array}$ & $\begin{array}{l}\mathbf{0 . 3 4 8} \\
(3.802)\end{array}$ & $\begin{array}{l}\mathbf{0 . 1 4 5} \\
(321.117)\end{array}$ \\
\hline 3 & $\begin{array}{l}0.226 \\
(14.696)\end{array}$ & $\begin{array}{l}0.204 \\
(4.523)\end{array}$ & $\begin{array}{l}0.246 \\
(373.535)\end{array}$ \\
\hline 4 & $\begin{array}{l}1.169 \\
(15.880)\end{array}$ & $\begin{array}{l}0.213 \\
(5.132)\end{array}$ & $\begin{array}{l}\mathbf{0 . 3 8 7} \\
(307.473)\end{array}$ \\
\hline 5 & $\begin{array}{l}0.215 \\
(16.782)\end{array}$ & $\begin{array}{l}0.167 \\
(4.412)\end{array}$ & $\begin{array}{l}0.195 \\
(350.582)\end{array}$ \\
\hline 6 & $\begin{array}{l}0.246 \\
(16.333)\end{array}$ & $\begin{array}{l}0.193 \\
(4.742)\end{array}$ & $\begin{array}{l}\mathbf{0 . 1 3 1} \\
(289.817)\end{array}$ \\
\hline 7 & $\begin{array}{l}0.488 \\
(15.563)\end{array}$ & $\begin{array}{l}0.188 \\
(6.170)\end{array}$ & $\begin{array}{l}0.197 \\
(328.913)\end{array}$ \\
\hline 8 & $\begin{array}{l}0.678 \\
(14.967)\end{array}$ & $\begin{array}{l}0.278 \\
(5.044)\end{array}$ & $\begin{array}{l}0.232 \\
(368.091)\end{array}$ \\
\hline 9 & $\begin{array}{l}0.207 \\
(16.511)\end{array}$ & $\begin{array}{l}0.161 \\
(4.792)\end{array}$ & $\begin{array}{l}0.277 \\
(307.994)\end{array}$ \\
\hline 10 & $\begin{array}{l}0.266 \\
(16.176)\end{array}$ & $\begin{array}{l}0.159 \\
(5.174)\end{array}$ & $\begin{array}{l}0.275 \\
(346.720)\end{array}$ \\
\hline
\end{tabular}

\section{ModulE}

We follow the judging criteria proposed by [15]. The basic idea of AHP is a multi-criteria decision-making and evaluation method combining qualitative and quantitative analysis. The elements of decision-making are decomposed into different levels, and the advantages and disadvantages of the decisionmaking schemes are sorted through some judgments. On this basis, qualitative and quantitative analysis is carried out. It makes people's thinking process hierarchical and quantitative and uses mathematics to provide a quantitative basis for analysis, decision-making, evaluation, prediction, and control. Let $\left\{A_{1}, A_{2} \ldots, A_{m}\right\}$ is the set of evaluating elements in each level. The pairwise comparison matrix is defined as.

$T=\left[\begin{array}{cccc}a_{11} & a_{12} & \cdots & a_{1 m} \\ a_{21} & a_{22} & \cdots & a_{2 m} \\ \vdots & \vdots & \ddots & \vdots \\ a_{m 1} & a_{m 2} & \cdots & a_{m m}\end{array}\right]$

The interpretations of each element and importance grading criteria are shown in Table IV. The process of computing weight may be divided into three main steps:

multiply all elements in each row of judge matrix T noted by Mim.

The interpretations of each element and importance grading criteria are shown in Table IV. The process of computing weight may be divided into three main steps: by $M i$.

multiply all elements in each row of judge matrix $T$ noted

$M_{i}=\prod_{j=1}^{m} a_{i j}, j=1,2,3 \cdots m$.

compute the value of $\mathrm{m}^{\text {th }}$ root of $\mathrm{M} i$ :

$\overline{W_{l}}={ }^{m} \sqrt{M_{i}}, i=1,2,3, \cdots, m$

the weight $W_{i}$ can be acquired by normalizing the vector $\left(W_{1}, W_{2}, \ldots, W_{m}\right)$, which can be finished by:

$W_{i}=\frac{\bar{W}_{i}}{\sum_{j=1}^{m} \bar{W}_{j}}$

We select two elements: Website (A1) and User(A2) as strategical level (Level2) while Six elements: Visiting speed (B1), website stability(B2), page ranking (B3), average person visit (B4), period of average person visit (B5) and users' comments (B6) are taken into account at criteria (Level3). The main outflow is shown in Fig. 1. After constructing a pairwise comparison judgment matrix. A necessary step is to perform an inconsistency test for each comparison judgment matrix. We follow the spirit of the Consistency Index (CI) proposed [28]. $\mathrm{CI}$ is defined as follows:

$C I=\frac{\lambda_{\max }-n}{n-n}$

where $\lambda \max$ is the maximum eigenvalue of matrix $\mathrm{T}$. Furthermore, consistency ratio (CR) can be computed by employing the following equation:

$C R=\frac{C I}{R I}$ 


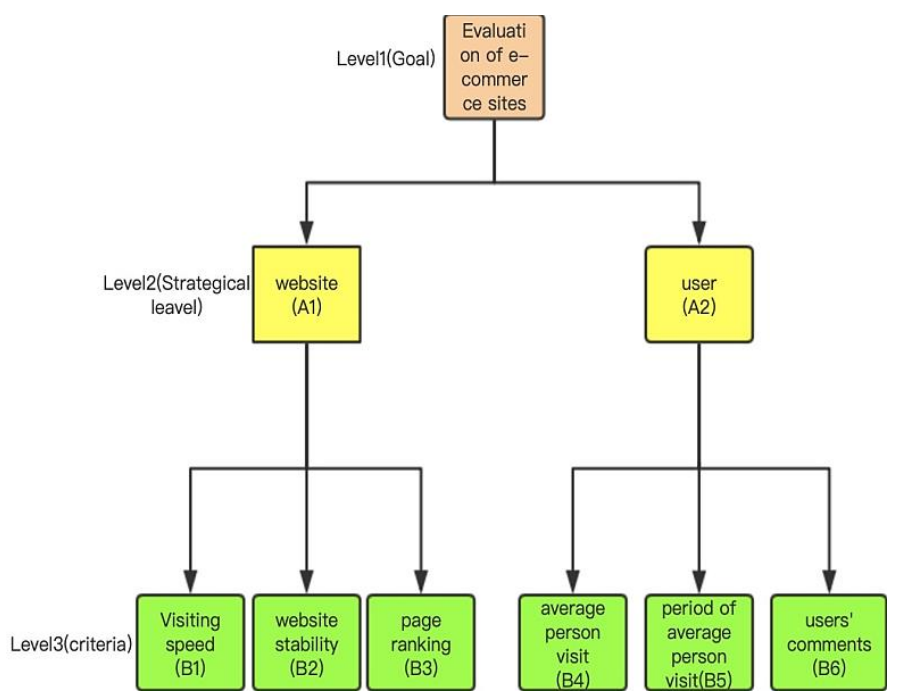

Fig. 1. Main Structure for AHP.

The RI is an index related to the dimension of matrix $\mathrm{T}$. The value of RI is shown as follows:

\begin{tabular}{|l|l|l|l|l|l|l|l|l|l|l|}
\hline Dimension & 1 & 2 & 3 & 4 & 5 & 6 & 7 & 8 & 9 & 10 \\
\hline RI & 0 & 0 & 0.52 & 0.89 & 1.12 & 1.26 & 1.36 & 1.41 & 1.46 & 1.49 \\
\hline
\end{tabular}

After getting the value of $\mathrm{CR}$, one may conclude that the pairwise comparison judgment matrix is desirable when $\mathrm{CR}<$ 0.1 ; otherwise, the pairwise comparison judgment matrix is unacceptable.

\section{A. Visiting Speed (B1)}

we use the same browser: Chrome: Mozilla/5.0. We employed the data from http://www.webkaka.com/WebCheck.aspx, where we set 10 times connected to a certain website and computed the average page-open time. Given that the faster visiting speed is, the higher grades should be acquired. Meanwhile, data normalization is necessary to eliminate the effect of different attributes' dimensions. Therefore, we set the final grade is calculated via the following formula:

Grade $=1-\frac{x_{\text {median }}-\min _{1 \leq i \leq 30}\left\{x_{j}\right\}}{\max _{1 \leq i \leq 30}\left\{x_{j}\right\}-\min _{1 \leq i \leq 30}\left\{x_{j}\right\}}$

where $x_{\text {media }}$ is the median of each website's data. The result is shown in Table I.

\section{B. Website Stability (B2)}

we use Ping to make sure the network server is available because Ping IP is much faster than trying to connect to it through any number of protocols. This is also a good way to test Internet connection latency. Similarly, we try 10 times and record each response time. The data is normalized to $[0,1]$ by applying Eq.1. The results are shown in Table I.

\section{Page Ranking (B3)}

It is referred to as PR (PageRank), from 0 to 10; the more significant the value, the more popular or important the page. In this study, we employ the google page rank algorithm(https://www.prchecker.info/checkpagerank.php).

The data is mapped into $[0,1]$ by di-viding 10 .

\section{Average Person Visits (B4)}

It is known person's visit could represent the popularity of a website. Therefore, we use the average page view (PV) from $1 / 10 / 2021-5 / 9 / 2021$ to quantify the popularity, and the data is normalized to $[0,1]$ by applying:

Grade $=\frac{x_{a}-\min _{1 \leq i \leq 30}\left\{x_{j}\right\}}{\max _{1 \leq i \leq 30}\left\{x_{j}\right\}-\min _{1 \leq i \leq 30}\left\{x_{j}\right\}}$

Where $x_{a}$ is the average of each website's data.

\section{E. Period of Average Person Visits (B5)}

We use page view(PV) to represent the average person's visit. A page view is the number of page views; Every time a user visits each page in the website, it is recorded once. Users visit the same page many times, and the number of visits is accumulated. The PV data is available at https://www.prchecker.info/checkpagerank.phpInthisstudyweal sotak as grade to represent the frequency. So as to precisely reveal the potential period of PV, we utilize the Morlet wavelet as a method. The Morlet wavelet is a continuous plane wave [30] modulated by Gauss function based on the following mother function:

$\Psi(t)=e^{i c t}\left(\mathrm{e}^{-\frac{t^{2}}{2}}-\sqrt{2} \mathrm{e}^{-\frac{c^{2}}{4}} \mathrm{e}^{-t^{2}}\right)$

The formula of discrete wavelet transform is

$W_{f}(a, b)=|a|^{-\frac{1}{2}} \sum_{i=1}^{N} f(i \delta t) \psi^{*}\left(\frac{i \delta t-b}{a}\right)$

where * denotes complex conjugate, a is the scale factor (related to period and frequency), $\mathrm{b}$ is translation factor (time position), $i$ is the time position label of data series, $f(t)$ is variable time series, $W_{f(a, b)}$ is wavelet coefficient; $\delta t$ is the difference of time series. The wavelet power spectrum is defined as:

$E_{a, b}=\left|W_{f}(a, b)\right|^{2}$

The total wavelet power spectrum Ea represents the energy density corresponding to different scales a, which is defined as

$E_{a}=\frac{1}{N} \sum_{b=1}^{N}\left|W_{f}(a, b)\right|^{2}$

Fig. 2 shows the results of Morlet wavelet analysis. There are two parts; the first is the contour of the real part of the wavelet coefficient, which has been mapped to color distribution, while the curve at the right region indicates the power spectrum of the wavelet coefficient as discussed in Eq.13. The power spectrum may help determine the main period in a certain time series; the peak in the wavelet power spectrum is regarded as the first/ main period discussed in this paper. In addition, the main period and its power have been marks as $\mathrm{Y}$ and $\mathrm{X}$ correspondingly. In general, all of (a), (b), (c) shows that cycle oscillations of a period of average person visit are very significant through the whole time domain.

\section{F. Users' Comments (B6)}

The users' comments are also a vital index to evaluate an ecommerce website [31]. We choose the newest iPhone 12 product as our target, and then we search for this same iphone12 product on each website. 200 comments were 
crawled from each website. Then we use the python package snownlp to grade each comment. The grade ranges from 0 to 1 ; if the grades are closer to 0 , the comments are more negative and vice versa. The final grade is the average of those figures. The outflow of comments' sentimental analysis is shown in Fig. 3. The basic statistics of sentimental scores are shown in Table II.

TABLE II. BASIC STATISTICS OF SENTIMENTS MARKS FOR EACH WEBSITE

\begin{tabular}{|l|l|l|l|}
\hline & SUNING & TAOBAO & JD \\
\hline Mean & 0.890912 & 0.896379 & 0.691769 \\
\hline Median & 0.976914 & 0.986995 & 0.858268 \\
\hline Maximum & 1 & 1 & 1 \\
\hline Minimum & 0.011091 & 0.011038 & 0 \\
\hline Std. Dev. & 0.187958 & 0.206043 & 0.352829 \\
\hline Skewness & -2.483815 & -2.731886 & -0.896659 \\
\hline Kurtosis & 9.190327 & 10.16932 & 2.284826 \\
\hline
\end{tabular}

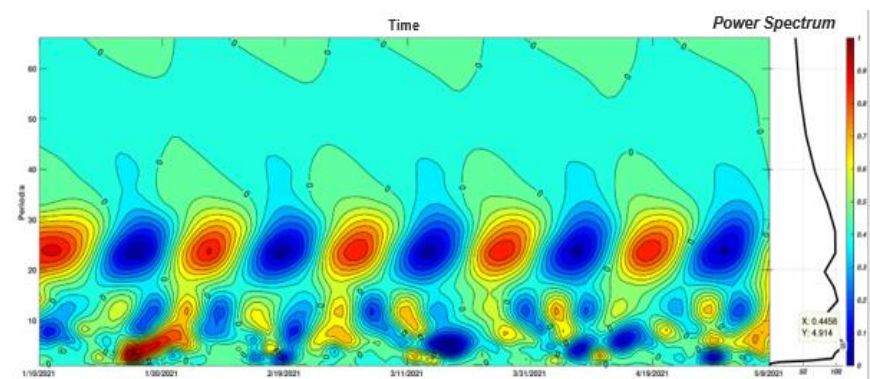

(a)

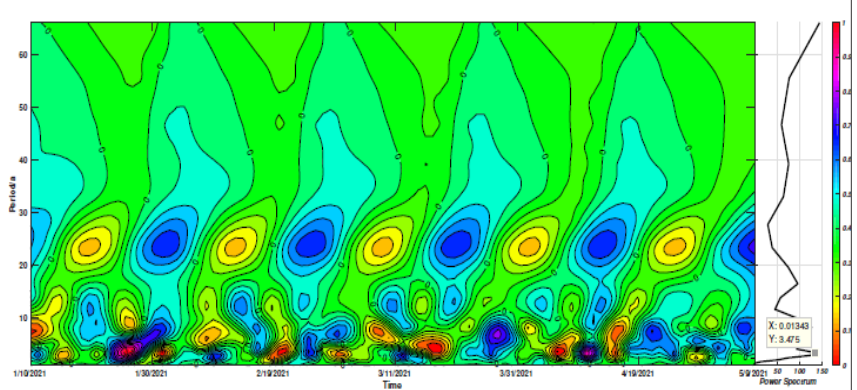

(b)

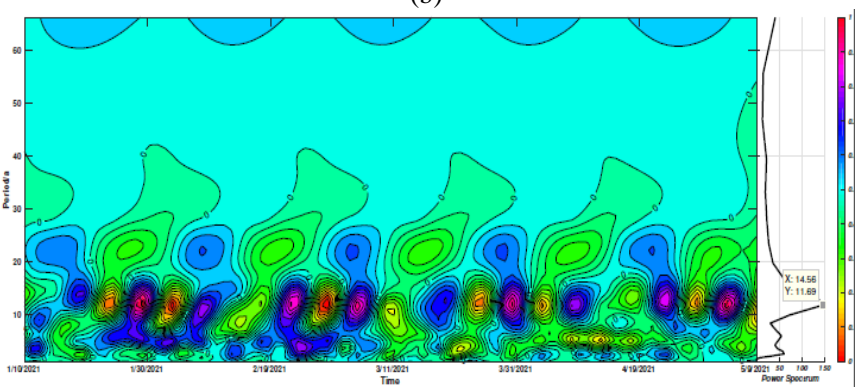

(c)

Fig. 2. (a) Wavelet Analysis for the Period of Average Person visit JD (b) Wavelet Analysis for the Period of Average Person Visit TAOBAO (c) Wavelet Analysis for the Period of Average Person visit SUNING.

Fig. 4 shows the results of comments' sentimental analysis; firstly, the users' favorable rate is $72 \%$. (b) and (c) are words cloud which may provide the potential reasons for the favorable rate. On the one hand, the majority of positive aspects concentrates on the following properties: High speed, nice appearance, high-quality photo; on the other hand, however, the positive comments mainly focus on the following aspects: the weak signal, the temperature of the phone is too hot, bad after-sale service, slow express.

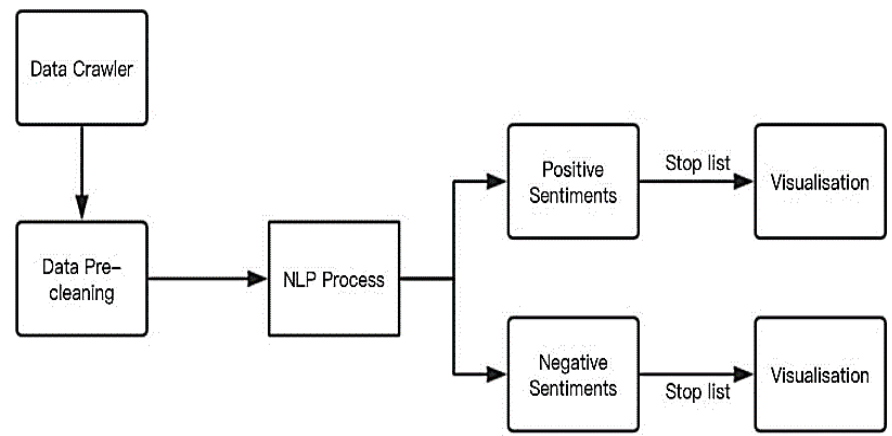

Fig. 3. Outflow of Comments' Sentimental Analysis.

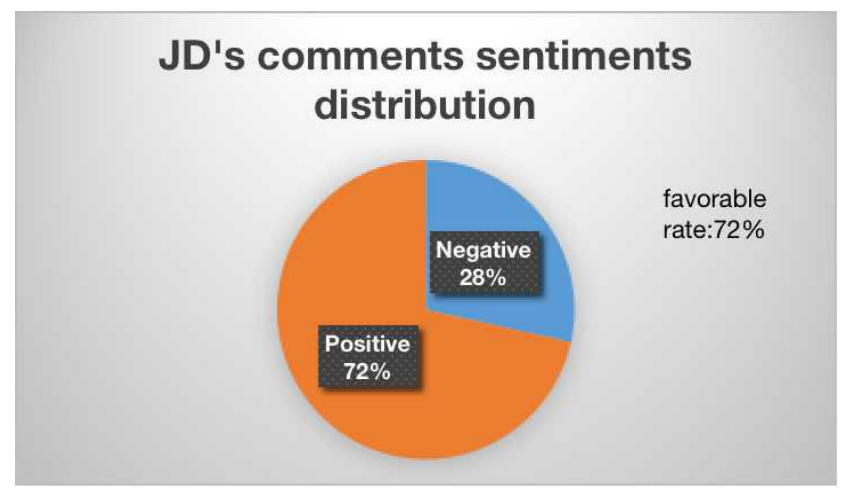

(a)

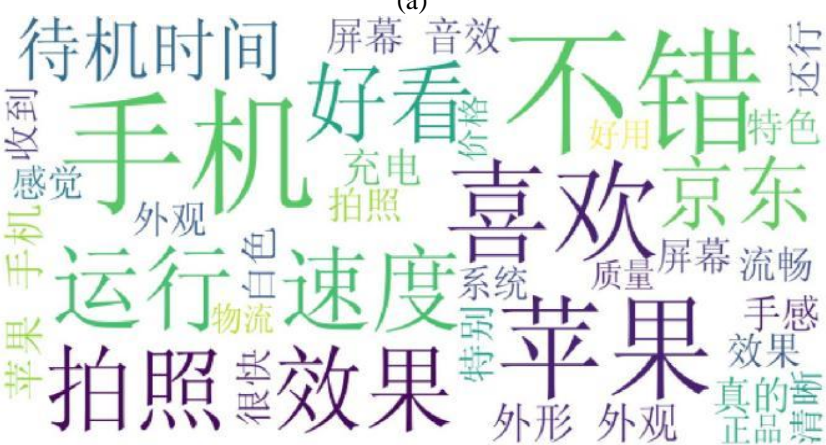

(b)

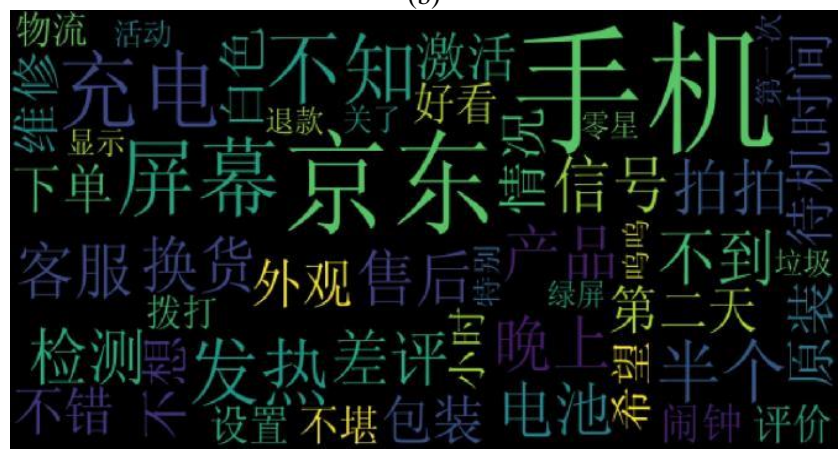

(c)

Fig. 4. (a) JD's Comments Sentiments Distribution (b) Positive Comments Words cloud of JD (c) Negative Comments Words cloud of JD. 


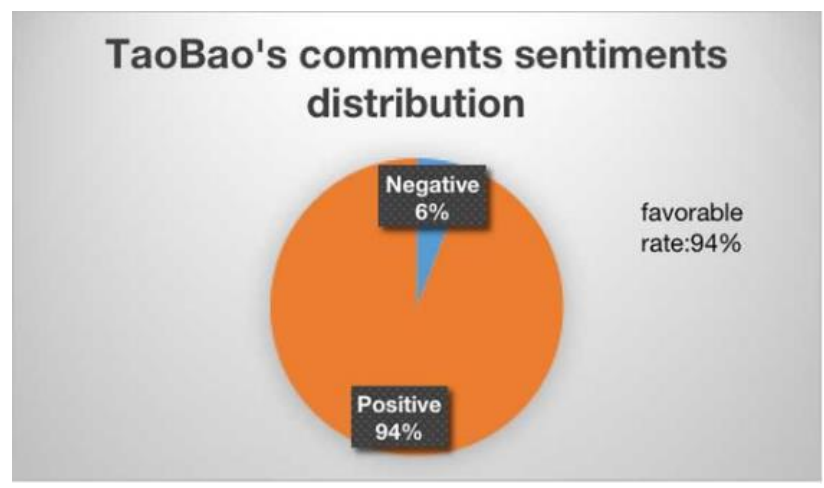

(a)

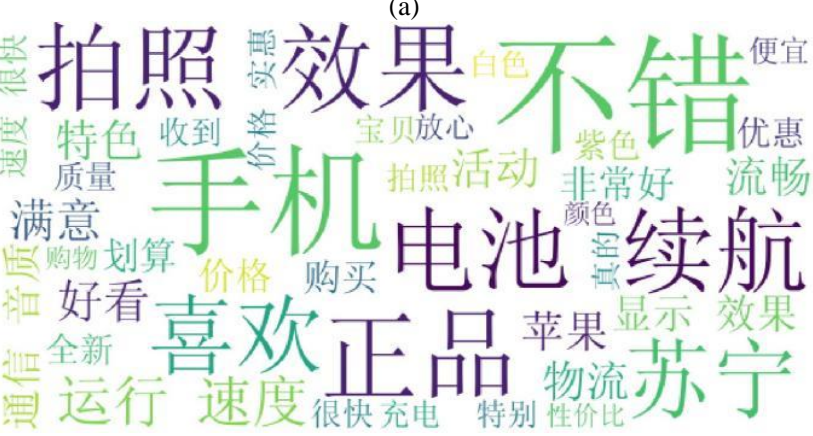

(b)

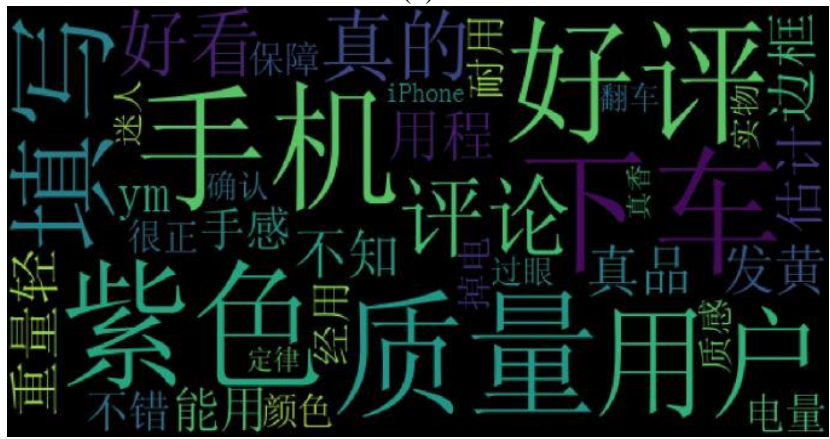

(c)

Fig. 5. (a) TAOBAO's Comments Sentiments Distribution (b) Positive Comments Words cloud of TAOBAO (c) Negative Comments Words cloud of TAOBAO.

Fig. 5 shows the results of comments' sentimental analysis for TAOBAO; firstly, the users' favorable rate is $94 \%$ which is better than JD's. (b) and (c) are words cloud which may provide the potential reasons for the favorable rate. On the one hand, the majority of positive aspects concentrate on the following properties: long-endurance, good brand, high-quality photo; on the other hand, however, the positive comments mainly focus on the following aspects: bad texture, ugly appearance color.

Fig. 6 shows the results of comments' sentimental analysis for SUNING; firstly, the users' favorable rate is $93 \%$ which is better than JD's but worse than TAOBAO's. (b) and (c) are words cloud which may provide the potential reasons for the favorable rate. On the one hand, most positive aspects concentrate on the following properties: long endurance, high efficiency, good battery; on the other hand, however, the positive comments mainly focus on the following aspects: bad appearance, ugly appearance color, slow expression.
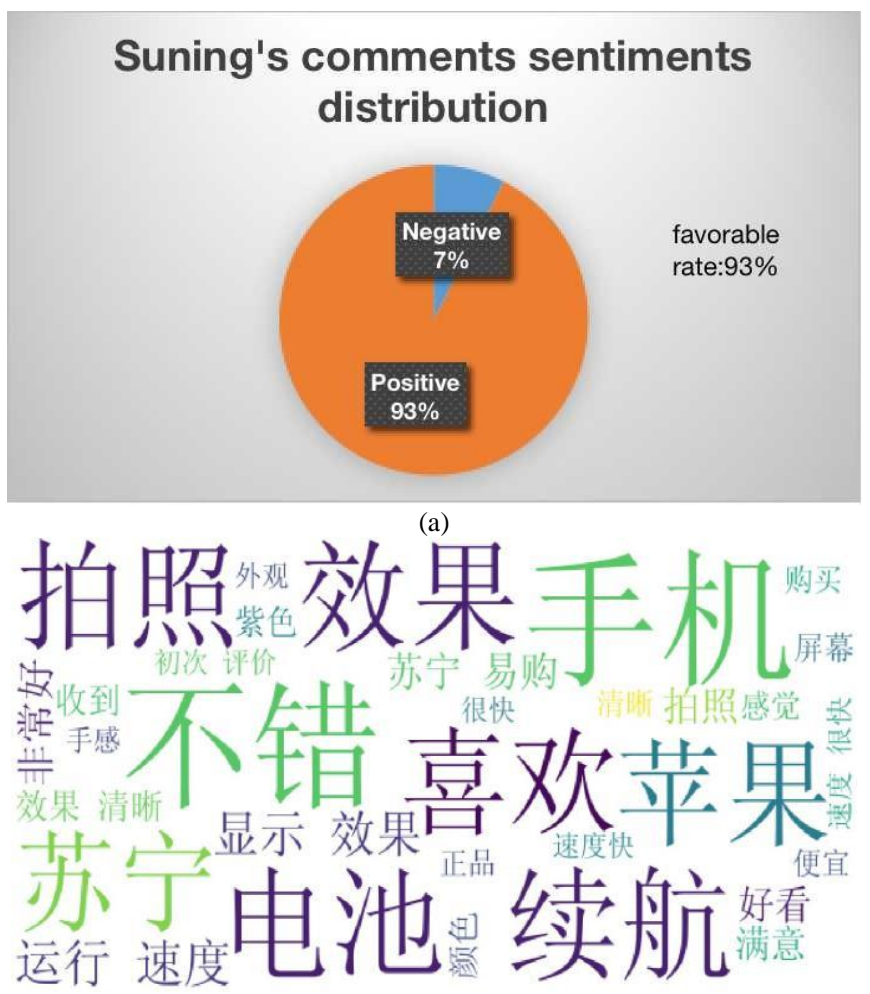

(b)

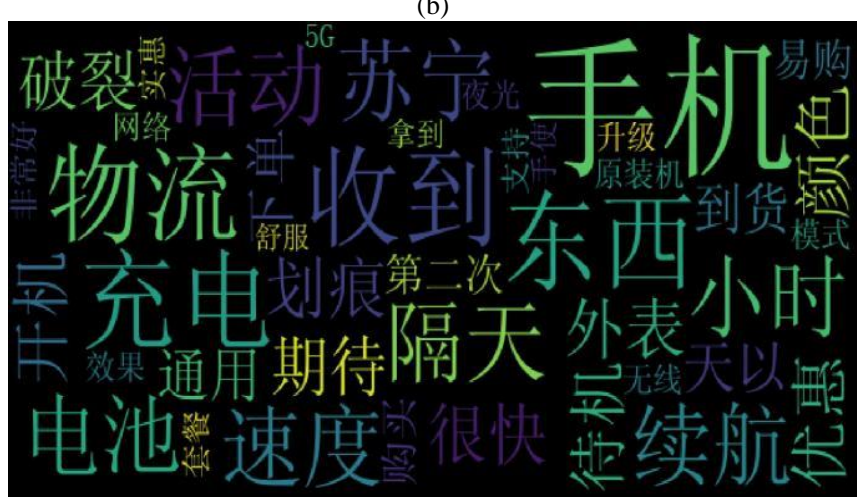

(c)

Fig. 6. (a) SUNING's Comments Sentiments Distribution (b) Positive Comments Words cloud of SUNING (c) Negative Comments Words cloud of SUNING.

\section{CONCLUDING REMARKS}

We constructed the pairwise comparison judgment matrix after the consultation and survey based on related fields. We assume that the website(A1) and user(A2) are equally important; visiting speed(B1) is of equal importance compared with website stability(B2); visiting speed(B1) is moderately important over page ranking(B3); Visiting speed(B1) is slightly important than Page ranking(B3). On the other hand, average person visits(B4) is slightly important than the period of average person visit(B5); users' comments(B6) is moderately critical compared to average person visit(B5); users' comments(B6) is critical than the period of average person visit(B5). Grounded on these assumptions, the pair-wise comparison judgment matrix is built as follows: 
$T_{A_{1}}=\left(\begin{array}{cccc}A_{1} & B_{1} & B_{2} & B_{3} \\ B_{1} & 1 & 1 & 3 \\ B_{2} & 1 & 1 & 2 \\ B_{3} & \frac{1}{3} & \frac{1}{2} & 1\end{array}\right), T_{A_{2}}=\left(\begin{array}{cccc}A_{2} & B_{4} & B_{5} & B_{6} \\ B_{4} & 1 & 2 & \frac{1}{3} \\ B_{5} & \frac{1}{2} & 1 & \frac{1}{4} \\ B_{6} & 3 & 4 & 1\end{array}\right)$

The corresponding weight vectors: WA1 = $[0.4434,0.3874,0.1692], \mathrm{WA} 2=[0.2385,0.1365,0.6250]$.

The maximum eigenvalue is $\lambda_{A 1}^{\max }=3.0183=$ $\lambda_{A 2}^{\max }, C I_{A 1}=0.0091=C I_{A 2}, C R_{A 1}=0.0158=\mathrm{CRA} 2$. Notice that both CR are less than 0.1 , which shows the consistency of each pairwise comparison judgment matrix. The Overall weight of each index can be easily calculated by multiplication: $W_{B i} * W_{A j,} i=1 . .3, j=1 . .2$. Table III shows the specific results. The total score of each e-commerce website is available in Table V. It is shown that TAOBAO is the best e-commerce website with a total score of $0.8233 / 1$, while JD is the second one with a total score of $0.7895 / 1$, and SUNING is the worst one compared with the TAOBAO and JD with a total score of $0.5955 / 1$. Based on the results, some suggestions are proposed for SUNING: first, the website stability should be improved largely. Second, Advertising on other websites is an important way to attract visitors to the website. Advertising will enhance the brand awareness of the website. Compared with traditional advertising, online advertising has many advantages. First of all, online advertising is not limited by time and space; the use of the Internet can send ads to every corner, as long as there is a network that can also browse advertising information at any time. In the past, the traditional form of advertising is single, and it has strict requirements and constraints on the content and form of communication. The form of online advertising is diversified, and advertising can appear in many forms. Users can interact with each other by playing with advertising rather than just seeing it so that users can see more public information and experience more product services.

TABLE III. OVERALL JUDGMENT WEIGHT OF EACH INDEX

\begin{tabular}{|l|l|l|l|}
\hline & $\begin{array}{l}\text { Strategical } \\
\text { Level }\end{array}$ & Criteria & $\begin{array}{l}\text { Overall } \\
\text { Weight }\end{array}$ \\
\cline { 2 - 4 } & \multirow{4}{*}{$\begin{array}{l}\text { A1 website } \\
(0.5)\end{array}$} & $\begin{array}{l}\text { B1 Visiting speed } \\
(0.4434)\end{array}$ & 0.2217 \\
\cline { 3 - 4 } $\begin{array}{l}\text { Evaluation of } \\
\text { E-commerce } \\
\text { websites }\end{array}$ & $\begin{array}{l}\text { B2 Website stability } \\
(0.3874)\end{array}$ & 0.1937 \\
\cline { 3 - 4 } & $\begin{array}{l}\text { B3 Page ranking } \\
(0.1692)\end{array}$ & 0.0846 \\
\cline { 3 - 4 } & $\begin{array}{l}\text { A2 User } \\
(0.5)\end{array}$ & $\begin{array}{l}\text { B4 Average person visit } \\
(0.2385)\end{array}$ & 0.1193 \\
\cline { 3 - 4 } & $\begin{array}{l}\text { B5 period of average } \\
\text { person visit } \\
(0.1365)\end{array}$ & 0.0683 \\
\cline { 3 - 4 } & $\begin{array}{l}\text { B6 Users' comments } \\
(0.6250)\end{array}$ & 0.3125 \\
\hline
\end{tabular}

TABLE IV. THE CRITERION TABLE

\begin{tabular}{|l|l|}
\hline The value of $a_{i j}$ & Interpretation \\
\hline 1 & equal importance \\
\hline 3 & moderate importance of a $i$ over a $j$ \\
\hline 5 & strong importance of a $i$ over a $j$ \\
\hline 7 & very importance of a $i$ over aj \\
\hline 9 & extreme importance of a $i$ over a $j$ \\
\hline $2,4,6,8$ & Intermediate values of $1,3,5,7$ \\
\hline reciprocal & $\begin{array}{l}\text { has reciprocal relations with respect to diagonally } \\
\text { symmetric element : } a i j \cdot a j i=1\end{array}$ \\
\hline
\end{tabular}

TABLE V. The TOtAL SCORE OF EACH E-COMMERCE Website

\begin{tabular}{|l|l|l|l|}
\hline & TAOBAO & JD & SUNING \\
\hline B1 & 0.8907 & 0.9350 & 0.9032 \\
\hline B2 & 0.9667 & 0.9971 & 0.1312 \\
\hline B3 & 0.7000 & 0.7000 & 0.7000 \\
\hline B4 & 0.6670 & 0.8361 & 0.2163 \\
\hline B5 & 0.2878 & 0.2035 & 0.0855 \\
\hline B6 & 0.8964 & 0.6918 & 0.8929 \\
\hline Total Score & 0.8233 & 0.7895 & 0.5955 \\
\hline
\end{tabular}

\section{DISCUSSION}

This work studied Chinese potential E-commerce Websites by applying AHP model. Three potential and competitive Ecommerce websites platforms are compared. Our results reveal that TAOBAO is the most competitive with the highest score: 0.8233 , JD with 07895 and SUNING with the lowest score:0.5955.

In the future, these works will be extended by following two aspects: First, other modern and effective evaluating models will be included and compared with current APH's results; Next, more related variables and hierarchies will be considered to develop a more completed E-commerce evaluating model.

\section{ACKNOWLEDGMENT}

The authors gratefully acknowledge the financial support from with Wenzhou-Kean University and Leading Talents of Provincial Colleges and Universities, ZhejiangChina(\#WB20200915000043).

\section{REFERENCES}

[1] Rania Nemat. Taking a look at different types of e-commerce. World Applied Programming, 1(2):100-104, 2011.

[2] Abdul Moktadir, Towfique Rahman, Charbel Jose Chiappetta Jabbour, Syed Mithun Ali, and Golam Kabir. Prioritiza-tion of drivers of corporate social responsibility in the footwear industry in an emerging economy: A fuzzy ahp ap-proach. Journal of cleaner production, 201:369-381, 2018. 
[3] Hemn Barzan Abdalla, Lu Zhen and Zhang Yuantu, "A New Approach of e-Commerce Web Design for Accessibility based on Game Accessibility in Chinese Market" International Journal of Advanced Computer Science and Applications(IJACSA), 12(8), 2021. http://dx.doi.org/10.14569/IJACSA.2021.0120801.

[4] Maggie CY Tam and VM Rao Tummala. An application of the ahp in vendor selection of a telecommunications system. Omega, 29(2):171$182,2001$.

[5] Ali Emrouznejad and Marianna Marra. The state of the art development of ahp (1979-2017): a literature review with a social network analysis. International Journal of Production Research, 55(22):6653-6675, 2017.

[6] Seleshi G Yalew, Ann van Griensven, Marlous L Mul, and Pieter van der Zaag. Land suitability analysis for agriculture in the abbay basin using remote sensing, gis and ahp techniques. Modeling Earth Systems and Environment, 2(2):1-14, 2016.

[7] Hong Wei Wang, Yu Song Yan, and Hua Wei Duan. Measuring the performance of e-commerce logistics system based on fuzzy-ahp. In Applied Mechanics and Materials, volume 505, pages 898-901. Trans Tech Publ, 2014.

[8] Rania Nemat. Taking a look at different types of e-commerce. World Applied Programming, 1(2):100-104, 2011.

[9] Blanca Perez-Gladish and Bouchra M'Zali. An ahp-based approach to mutual funds' social performance measurement. International Journal of Multicriteria Decision Making, 1(1):103-127, 2010.

[10] GUO Kai. The competitiveness evaluation of e-commerce website based on ahp-entropy. In 2010 International Confer-ence on E-Business and EGovernment, pages 392-394. IEEE, 2010.

[11] Hai-Min Lyu, Yong-Xia Wu, Jack Shuilong Shen, and An-Nan Zhou. Assessment of social-economic risk of chinese dual land use system using fuzzy ahp. Sustainability, 10(7):2451, 2018.

[12] M'onica Garc'ia-Mel'on, Blanca P'erez-Gladish, Tom'as G'omezNavarro, and Paz Mendez-Rodriguez. Assessing mu-tual funds' corporate social responsibility: a multistakeholder-ahp based methodology. Annals of Operations Research, 244(2):475-503, 2016.

[13] Francesca Abastante, Salvatore Corrente, Salvatore Greco, Alessio Ishizaka, and Isabella M Lami. Choice architecture for architecture choices: Evaluating social housing initiatives putting together a parsimonious ahp methodology and the choquet integral. Land Use Policy, 78:748-762, 2018.

[14] Kamal M Al-Subhi Al-Harbi. Application of the ahp in project management. International journal of project manage-ment, 19(1):1927, 2001.

[15] Thomas L Satty et al. The analytic hierarchy process, 1980.

[16] Aminuddin Md Arof. The application of a combined delphi-ahp method in maritime transport research-a review. Asian Social Science, 11(23):73, 2015.

[17] Gang Chen. Analyzing criteria and sub-criteria for the corporate social responsibility-based supplier selection process using ahp. The International Journal of Advanced Manufacturing Technology, 68(14):907-916, 2013.
[18] Xu, L, Kumar, DT, Shankar, KM, Kannan, D \& Chen, G 2013, 'Analyzing criteria and sub-criteria for the corporate social responsibility-based supplier selection process using AHP', International Journal of Advanced Manufacturing Technology, vol. 68, no. 1-4, pp. 907-916. https://doi.org/10.1007/s00170-013-4952-7.

[19] Jia Yu, Jianrong Yao, and Yuangao Chen. Credit scoring with ahp and fuzzy comprehensive evaluation based on be-havioural data from weibo platform. Tehni cki vjesnik, 26(2):462-470, 2019.

[20] Xiong Ying, Guang-Ming Zeng, Gui-Qiu Chen, Lin Tang, Ke-Lin Wang, and Dao-You Huang. Combining ahp with gis in synthetic evaluation of eco-environment quality - a case study of hunan province, china. Ecological modelling, 209(2-4):97-109, 2007.

[21] Deng-Neng Chen, Chih-Wei Tseng, and Chia-Yi Lin. Applying fuzzy ahp on product selection service in e-commerce. In 2011 International Joint Conference on Service Sciences, pages 198-202. IEEE, 2011.

[22] Fereshteh Alizadeh and Mina Lahiji. Suitable delivery system in small ecommerce companies. Journal of Humanities Insights, 2(04):167-171, 2018.

[23] A Ishak, R Ginting, and W Wanli. Evaluation of e-commerce services quality using fuzzy ahp and topsis. In IOP Con-ference Series: MaterialsScience and Engineering, volume 1041, page 012042. IOP Publishing, 2021.

[24] Xuhua Chen. Marine transport efficiency evaluation of cross-border ecommerce logistics based on analytic hierarchy process. Journal of Coastal Research, 94(SI):682-686, 2019.

[25] Hong Wei Wang, Yu Song Yan, and Hua Wei Duan. Measuring the performance of e-commerce logistics system based on fuzzy-ahp. In Applied Mechanics and Materials, volume 505, pages 898-901. Trans Tech Publ, 2014.

[26] GUO Kai. The competitiveness evaluation of e-commerce website based on ahp-entropy. In 2010 International Confer-ence on E-Business and EGovernment, pages 392-394. IEEE, 2010.

[27] Aulia Ishak et al. Evaluation and selection of e-commerce service quality using fuzzy ahp method. In IOP Conference Series: Materials Science and Engineering, volume 1003, page 012152. IOP Publishing, 2020.

[28] Panova, Y., Tan, A., Hilmola, OP. et al. Evaluation of e-commerce location and entry to China - implications on shipping and trade. J. shipp. trd. 4, 6 (2019). https://doi.org/10.1186/s41072-019-0045-6.

[29] Christopher Torrence and Gilbert P Compo. A practical guide to wavelet analysis. Bulletin of the American Meteoro-logical society, 79(1):61-78, 1998.

[30] Thomas L Saaty. How to make a decision: the analytic hierarchy process. European journal of operational research, 48(1):9-26, 1990.

[31] Hong Wei Wang, Yu Song Yan, and Hua Wei Duan. Measuring the performance of e-commerce logistics system based on fuzzy-ahp. In Applied Mechanics and Materials, volume 505, pages 898-901. Trans Tech Publ, 2014. 